\title{
Correction to: Structural and solution chemistry, antiproliferative effects, and serum albumin binding of three pseudohalide derivatives of auranofin
}

\author{
Damiano Cirri (D) Maria Giulia Fabbrini - Lara Massai - Serena Pillozzi • \\ Annalisa Guerri - Alessio Menconi - Luigi Messori - Tiziano Marzo • \\ Alessandro Pratesi
}

Published online: 19 November 2019

(C) Springer Nature B.V. 2019

Correction to: Biometals https://doi.org/10.1007/ s10534-019-00224-1

In the initial online publication, the given name of the first author was incorrectly displayed and should have read Damiano. The original article has been corrected and the proper representation of the authors' names and their affiliation is also listed here.

Publisher's Note Springer Nature remains neutral with regard to jurisdictional claims in published maps and institutional affiliations.
The original article can be found online at https:// doi.org/10.1007/s10534-019-00224-1.

D. Cirri $(\bowtie)$ · M. G. Fabbrini · L. Massai ·

A. Guerri · L. Messori ( $\square)$

Department of Chemistry, University of Florence, Via

della Lastruccia 3, 50019 Sesto Fiorentino, Italy

e-mail: damiano.cirri@unifi.it

L. Messori

e-mail: luigi.messori@unifi.it

\section{S. Pillozzi · A. Menconi}

Department of Experimental and Clinical Medicine, University of Florence, Viale GB Morgagni 50,

50134 Florence, Italy

T. Marzo

Department of Pharmacy, University of Pisa, Via

Bonanno Pisano 6, 56126 Pisa, Italy

A. Pratesi

Department of Chemistry and Industrial Chemistry,

University of Pisa, Via G. Moruzzi 13, 56124 Pisa, Italy 